Research Article

\title{
The Short Tandem Repeat of the DMT1 Gene as a Molecular Marker of Elite Long-Distance Runners
}

\author{
Gerile Wuyun, ${ }^{1}$ Yang $\mathrm{Hu} \mathbb{D}^{2},{ }^{2}$ Zihong $\mathrm{He},{ }^{3}$ Yanchun $\mathrm{Li}^{2}$ and $\mathrm{Xu} \mathrm{Yan}^{4,5}$ \\ ${ }^{1}$ Institute of Sport, Inner Mongolia Normal University, China \\ ${ }^{2}$ China Institute of Sport and Health Science, Beijing Sport University, China \\ ${ }^{3}$ Biology Center, China Institute of Sport Science, China \\ ${ }^{4}$ Institute for Health and Sport, Victoria University, Australia \\ ${ }^{5}$ Australian Institute for Musculoskeletal Sciences, Australia \\ Correspondence should be addressed to Yang Hu; huyang@bsu.edu.cn
}

Received 14 June 2019; Revised 1 October 2019; Accepted 18 October 2019; Published 23 November 2019

Academic Editor: Byung-Hoon Jeong

Copyright (C) 2019 Gerile Wuyun et al. This is an open access article distributed under the Creative Commons Attribution License, which permits unrestricted use, distribution, and reproduction in any medium, provided the original work is properly cited.

\begin{abstract}
The DMT1 gene encodes divalent metal transporter 1, a membrane iron transport protein. Divalent metal transporter 1 influences cellular iron availability, which might further affect aerobic exercise capacity. Short tandem repeat (STR) polymorphisms have been used as genetic markers in the literature, yet the STR polymorphisms of the DMT1 gene have not been well studied. In this current study, we explored the polymorphisms of the DMT1 gene in a group of elite long-distance runners and controls, by using the PCRRFLP (Restriction Fragment Length Polymorphism) and Gene scan technology. We found that the genotype frequency of the homozygous $258 \mathrm{bp}$ STR polymorphism of the DMT1 gene $(258 \mathrm{bp} / 258 \mathrm{bp})$ was significantly higher in the athlete group than in the controls $\left(\chi^{2}=14.01, p=0.006\right)$ so does the allele frequency of the $258 \mathrm{bp}$ STR polymorphism $\left(\chi^{2}=12.867, p=0.008\right)$. These data suggested that the STR polymorphism of the DMT1 gene might be correlated with aerobic exercise capacity and the $258 \mathrm{bp}$ homozygous ( $25 \mathrm{bp} / 258 \mathrm{bp}$ ) could be used as a molecular marker for the talent identification of elite long-distance runners.
\end{abstract}

\section{Introduction}

Divalent metal transporter 1 (DMT1) is a major membrane transport protein, which uptakes nonheme iron within the lumen [1]. The DMT1 gene is expressed in many human tissues, such as the small intestine, kidney, liver, and lung [2]. It is known that the human proximal small intestine is the main site for iron absorption, in which iron element exists in the form of $\mathrm{Fe}^{2+} . \mathrm{Fe}^{2+}$ could enter into blood circulation via the mediation of Ferroportin1 (FPN1) and Hephaestin (HP) or enter into epithelial cells with the mediation of DMT1 [3]. Iron element plays an important role in constituting Hemoglobin $(\mathrm{Hb})$ and Myoglobin $(\mathrm{Mb})$. Therefore, iron element is important for exercise, yet its function can be characterized by duality [4]. A deficiency of iron element affects the maximal uptake of oxygen $\left(\mathrm{VO}_{2} \mathrm{max}\right)$ of athletes and is associated with a decreased exercise capacity, due to the reduction in protein synthesis, the decreased oxygen transporting and storing capacity, and the fall of enzymatic activities and hormones level, as well as the reduction in phosphorylation capacity and decreased adenosine triphosphate (ATP) production [5]. On the other hand, excessive iron element also affects exercise ability. Free iron element induces the production of free radicals, leading to an increase of human lipid peroxidation level and even tissue damage. Thus, both iron deficiency and iron excess can directly affect exercise ability [6].

Human exercise ability has distinct individual differences, which have been attributed from both the Nurture side (diet and training) [7, 8] and the Nature side (genetics) [9-16]. The human DMT1 gene is located in 12q13, with 17 exons. The expression of the DMT1 gene depends on the basis of the organism or cell iron status [17]. Lee et al. first discovered 5 polymorphic sites in the third intron of the human DMT1 gene, as well as 1 short tandem repeat (STR) microsatellite polymorphism [18]. STR is a short tandem repeat sequence, with its core sequence $2-6 \mathrm{bp}$ in length. STR mainly exists in the noncoding regions of the genome, 
TABLE 1: Basic information of the athlete group.

\begin{tabular}{lccccccc}
\hline Groups & \multirow{2}{*}{ No. of people } & \multirow{2}{*}{ Age (year) } & Height $(\mathrm{cm})$ & Weight $(\mathrm{kg})$ & \multicolumn{2}{c}{ Type of sports } & \multicolumn{2}{c}{$\begin{array}{c}\text { Athletic level } \\
\text { 5, 10 km }\end{array}$} & Marathon & International & National \\
\hline Athlete (total) & 123 & $23.10 \pm 5.10$ & $169.29 \pm 7.50$ & $55.53 \pm 7.45$ & 92 & 31 & 43 \\
Athlete (male) & 62 & $24.27 \pm 11.87$ & $174.95 \pm 5.13$ & $61.48 \pm 4.77$ & 47 & 15 & 11 \\
Athlete (female) & 61 & $20.84 \pm 5.31$ & $163.53 \pm 4.56$ & $49.48 \pm 3.97$ & 45 & 16 & 32 \\
\hline
\end{tabular}

Note: data are expressed in average \pm standard deviation.

TABLE 2: Basic information of the control group.

\begin{tabular}{lcccc}
\hline Groups & No. of people & Age (year) & Height $(\mathrm{cm})$ & Weight $(\mathrm{kg})$ \\
\hline Controls (total) & 102 & $20.31 \pm 1.20$ & $168.88 \pm 8.11$ & $62.84 \pm 11.87$ \\
Controls (male) & 52 & $20.29 \pm 1.15$ & $174.60 \pm 5.88$ & $68.36 \pm 12.24$ \\
Controls (female) & 50 & $20.33 \pm 1.27$ & $162.57 \pm 4.86$ & $56.80 \pm 7.90$ \\
\hline
\end{tabular}

Note: data are expressed in average \pm standard deviation.

which is related to the genetic recombination and gene express regulation, and maintains genome stability [19]. The STR located in the gene exon region has been reported to encode protein [20]. STR is widely existed in the genome, with a low recombination rate. Because of its compliance with Mendelian Inheritance, i.e., its codominant heredity, STR is widely used in association studies including genetic phenotype, gene mapping, genetic disease diagnosis, and paternity tests. It is therefore known as the second generation of genetic markers.

In this current study, we explored the STR microsatellite polymorphisms of the DMT1 gene in elite long-distance runners and the controls, with the aim to identity molecular genetic markers for talent identification of elite longdistance runners.

\section{Materials and Methods}

2.1. Research Subjects. The study has been approved by the ethics committee of Beijing Sport University; all the participants have signed a consent form. The study has been conducted according to the principles of the Declaration of Helsinki [21].

For the athlete group, there are 123 elite long-distance runners, all from the northern region of China, all in good health, and all belonging to Han nationality. The details are shown in Table 1.

For the control group, there are 102 college students from Beijing Sport University, without any professional training, all from the northern region of China, all in good health, and all belonging to Han nationality. The details are shown in Table 2.

2.2. Experimental Method. DNA was extracted using the Wizard ${ }^{\circledR}$ Genomic DNA Purification Kit (A1125, Promega, Wisconsin, USA). The STR polymorphism (rs2076732) of the DMT1 gene was obtained from the NCBI SNP library. The STR polymorphism is located in intron 3 of the DMT1

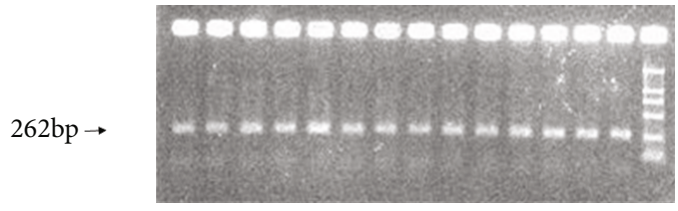

FIgUre 1: A presentative agarose picture of the PCR product of the DMT1 gene STR polymorphism.

gene, with the repetitive sequence: (TA) 6/7 (CA) 11/12/13 CCCCATCTA (TATC) 3 (TCTG) 4/5 TCCG TCTA 5/6/7/9/10. The PCR primers were designed with the Primer 5.0 software and were synthesized by Sangon Biotech (Shanghai, China). The primer sequences are as follows: forward primer: $5^{\prime}$-ggaTGGCTCaagTTCagcag-3' (TAMRA fluorescent tags $5^{\prime}$ item); reverse primer: $5^{\prime}$-TGGGCTatgGTTGTGccaCTG-3'. The PCR amplification fragments are $262 \mathrm{bp}$ in length (Figure 1).

The distribution of the DMT1 gene STR polymorphisms was determined by the ABI 377 DNA Sequencer (Applied Biosystems, Massachusetts, USA) with the GeneScan detection technology (Figure 2).

2.3. Data Analysis. Data was analyzed with the SPSS15.0. A $\chi^{2}$ test was used to check if the genotype frequency and allele frequency are in line with the Hardy-Weinberg equilibrium and to analyze the differences of the allele frequencies and genotype frequencies between the athlete group and the control group. A $p<0.05$ is considered significant.

\section{Results}

A Hardy-Weinberg equilibrium was obtained for each genotype distribution frequency $(p>0.05$, data were shown in Tables 3 and 4). 


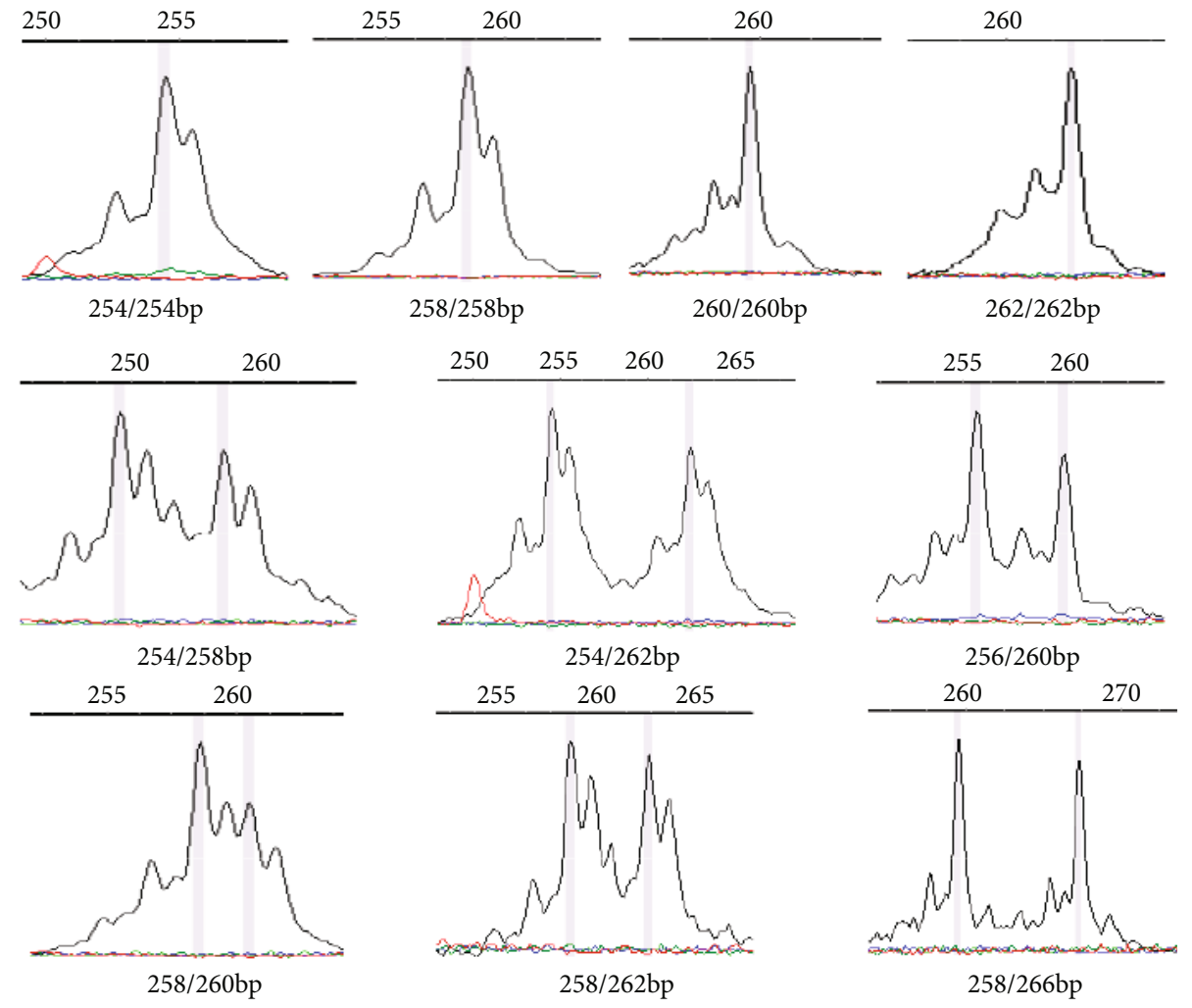

FIGURE 2: Representative picture of the GeneScan genotype data of the DMT1 gene STR polymorphism.

According to the $\chi^{2}$ test results, there were significant differences in the $258 \mathrm{bp} / 258 \mathrm{bp}$ genotype frequency between the athlete group and the control group $\left(\chi^{2}=14.011, p=\right.$ 0.006 ). When the athletes were further categorized as the 5 , $10 \mathrm{~km}$ group or the marathon group, the $258 \mathrm{bp} / 258 \mathrm{bp}$ genotype frequency was significantly different between the 5, $10 \mathrm{~km}$ group and the control group $\left(\chi^{2}=11.910, p=0.017\right)$ but did not reach significance between the marathon group and the control group $\left(\chi^{2}=5.762, p=0.217\right)$. We then checked whether there was a gender difference in the genotype frequency of the DMT1 STR polymorphism; we did not find a significant difference between males and females among the athlete group or the control group. However, we did found that the $258 \mathrm{bp} / 258$ bp genotype frequency was significantly higher in the male athletes than in the male controls and significantly higher in the female athletes than in the female controls.

We then checked the allele frequency of the $258 \mathrm{bp}$ allele, which was significant differently between the athlete group and the control group $\left(\chi^{2}=12.867, p=0.008\right.$, Table 5), as well as the $5,10 \mathrm{~km}$ group and the control group $\left(\chi^{2}=11.082, p=0.021\right)$. There was no significant difference in the frequency of the $258 \mathrm{bp}$ allele between the marathon group and the control group $\left(\chi^{2}=5.516, p=0.212\right)$. When we further divided the athletes into males and females, the allele frequency was significantly higher in the male athletes and female athletes, when compared with the male controls and female controls, respectively.

\section{Discussion}

In this current study, we explored the STR polymorphisms of the DMT1 gene; we have identified six alleles: $254 \mathrm{bp}, 256 \mathrm{p}$, $258 \mathrm{bp}, 260 \mathrm{bp}, 262 \mathrm{bp}$, and $266 \mathrm{bp}$. There are five alleles and a total of eight genotypes in the athlete group, while the control group has six alleles and ten genotypes; both groups are in line with the Hardy-Weinberg equilibrium. A previous study reported three alleles $(260 \mathrm{bp}, 262 \mathrm{bp}$, and $264 \mathrm{bp}$ ) in eight healthy Caucasians, which included two $260 \mathrm{bp}$ homozygous, two $264 \mathrm{bp}$ homozygous, three $260 / 262$ bp heterozygous, and one 260/264 bp heterozygous [22]. This discrepancy could be due to the small sample size of the previous study (only eight individuals). It is also possible that there could be differences with the distribution of DMT1 STR polymorphisms between different ethnic groups (Caucasians for the previous study and Asians for the current study).

Data from this current study suggested that there was a strong association between the DMT1 STR polymorphism and likelihood of being elite long-distance runners. The frequency of $258 \mathrm{bp}$ homozygous was significantly higher in the athlete group $(55.29 \%)$ than in the control group (41.04\%), similar for the $5,10 \mathrm{~km}$ athlete group (58.70\%). The expression of the DMT1 gene has been associated with iron levels in the body, which might further affect aerobic exercise capacity. Previous studies have reported an increased iron loss in long-distance runners [23, 24]; iron loss 


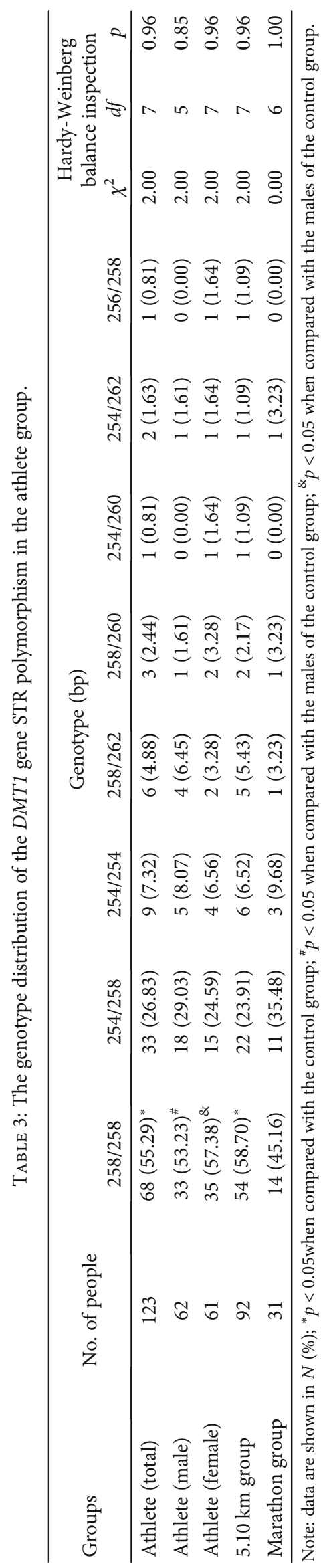




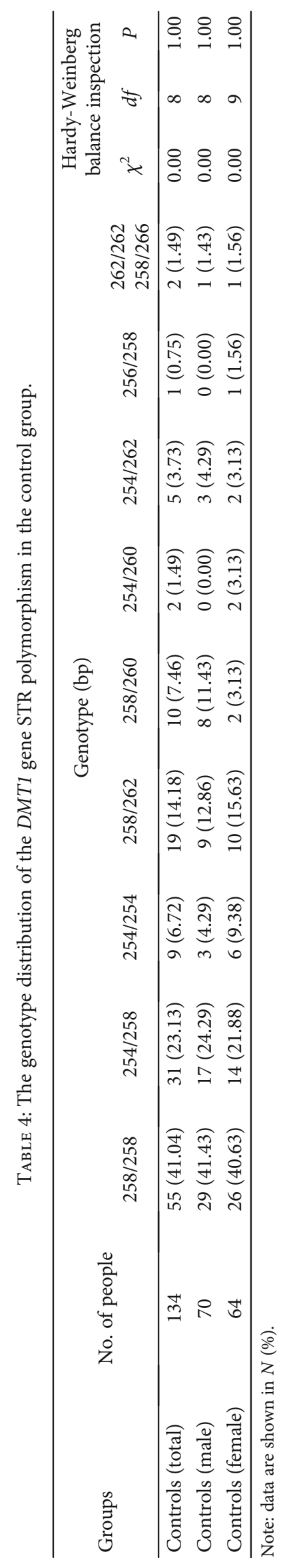


TABLE 5: The allele distribution of the DMT1 gene STR polymorphism.

\begin{tabular}{|c|c|c|c|c|c|c|c|}
\hline \multirow{2}{*}{ Groups } & \multirow{2}{*}{ No. of people } & \multicolumn{6}{|c|}{ Allele (bp) } \\
\hline & & 254 & 256 & 258 & 260 & 262 & 266 \\
\hline Athlete (total) & 123 & $54(21.95)$ & $1(0.41)$ & $179(72.76)^{* *}$ & $4(1.63)$ & $8(3.25)$ & - \\
\hline Athlete (male) & 62 & $29(23.39)$ & $0(0.00)$ & $89(71.77)^{\#}$ & $1(0.81)$ & $5(4.03)$ & - \\
\hline Athlete (female) & 61 & $25(20.49)$ & $1(0.82)$ & $90(73.77)^{\&}$ & $3(2.46)$ & $3(2.46)$ & - \\
\hline $5,10 \mathrm{~km}$ group & 92 & $36(19.57)$ & $1(0.54)$ & $138(75.00)^{*}$ & $3(1.63)$ & $6(3.26)$ & - \\
\hline Marathon group & 31 & $18(29.03)$ & $0(0.00)$ & $41(66.13)$ & $1(1.61)$ & $2(3.23)$ & - \\
\hline Control (total) & 134 & $56(20.90)$ & $1(0.37)$ & $172(64.18)$ & $12(4.48)$ & $26(9.70)$ & $1(0.37)$ \\
\hline Control (male) & 70 & $26(18.57)$ & $0(0.00)$ & $92(65.71)$ & $8(5.71)$ & $14(10.00)$ & $0(0.00)$ \\
\hline Control (female) & 64 & $30(23.44)$ & $1(0.78)$ & $80(62.50)$ & $4(3.13)$ & $12(9.38)$ & $1(0.78)$ \\
\hline
\end{tabular}

Note: data are shown in $N(\%) ;{ }^{*} p<0.05$ when compared with the control group; ${ }^{* *} p<0.01$ when compared with the control group; ${ }^{*} p<0.05$ when compared with the male controls.

can induce the expression of the DMT1 gene in theduodenum cells [25], while moderate exercise can also increase the expression of the DMT1 gene in duodenum cells [26]. Therefore, both iron deficiency and exercise can increase the expression of the DMT1 gene, leading to an increased duodenal iron absorption and iron endosome transportation, which ensures the iron demand of the human body. In addition, the $\mathrm{G}>\mathrm{C}$ transversion of the last nucleotide of the human DMT1 gene exon has been associated with iron deficiency erythropoiesis and a decreased Hb level [27]. Fleming et al. have also found that the glycine-arginine mutation (G185R) of the DMT1 gene reduced intestinal iron absorption in Belgrade rats [28].

No research to date has reported the function of the DMT1 gene STR polymorphism; we reported the association of the DMT1 gene STR polymorphism with the likelihood of being elite long-distance runners. We speculate the mechanisms of the DMT1 gene STR polymorphism influencing aerobic exercise ability through the regulation of DMT1 gene expression, which further influence intestinal iron absorption and iron status. It is known that iron status affects exercise performance [29]. The prevalence of iron deficiency anemia is higher in athletic populations than sedentary controls, especially in long-distance runners [29]. While a moderate iron supplementation is effective in preventing decline in the iron status of female collegiate swimmers during a competitive season [30], the STR polymorphisms might regulate DMT1 gene expression via two possible mechanisms. (1) The STR polymorphisms might lead to alternative splicing of the DMT1 gene. A recent study has proposed that there is a link between short tandem repeats and translation initiation site selection in humans [31]. Previous studies have reported the existence of isoforms of DMT1 mRNA [32, 33] and protein [33], suggesting alternative splicing of the DMT1 gene. It is plausible that the STR polymorphisms lead to alternative splicing of the DMT1 gene, which further affects the expression of the DMT1 gene. (2) DMT1 might interact with hepcidin to control iron homeostasis. Hepcidin is the main iron regulatory hormone responsible for the maintenance of iron homeostasis, which controls the absorption of dietary iron and the distribution of iron among tissues and organs in the body [34]. Hepcidin level was reported to increase significantly 3,6 , and 24 h post exercise and then declined after that, returning to baseline at $72 \mathrm{~h}$ post exercise $[35,36]$. Hepcidin was reported to decrease after 3 weeks of training in female runners [37] but increased after an intensified training period in well-trained female long-distance runners [38]. On the other hand, hepcidin treatment has been shown to decrease DMT1 expression and iron uptake in intestinal cells [39] and in mouse intestines [40], suggesting the regulation of $D M T 1$ by hepcidin. It is possible that the STR polymorphisms affect the regulation capacity of hepcidin on DMT1, which leads to varied DMT1 expression and different exercise capacity.

There are several limitations for the current study. (1) We only checked the STR polymorphisms of the DMT1 gene, which are located at the intron region of the DMT1 gene. There are a number of other DMT1 polymorphisms reported previously, but we have not checked whether there is an addictive effect of different polymorphisms. There were no associations between DMT1 $1303 \mathrm{C}>\mathrm{A}$ polymorphism in the exon region and iron overload in Chinese Parkinson's disease patients [41]. The $1254 \mathrm{~T}>\mathrm{C}$ polymorphism in the exon region of the DMT1 gene has been associated with Parkinson's disease [42]. However, there is no study that checked the effects of those two polymorphisms on the expression of the DMT1 gene. On the other hand, another intronic DMT1 polymorphism, DMT1 IVS4+44C $>$ A, has been associated with increased DMT1 gene expression and iron level. The C allele of the DMT1 IVS4+44C >A polymorphism is more prevalent in Parkinson's disease patients, a population known to have elevated iron accumulation in the substantia nigra, together with the increased expression of DMT1 gene expression [41]. The DMT1 IVS4 C(+) allele occurred more frequently in Wilson's disease population than in the healthy controls, while iron dyshomeostasis has been characterized in Wilson's disease [43]. The CC genotype of the DMT1 gene IVS4+44C>A polymorphism is associated with increased risk of age-related macular degeneration, a condition related to increased reactive oxygen species, which might be caused by the increased iron ions [44]. The AA genotype of the DMT1 IVS4+44C >A polymorphism has reported a four-fold increase of the risk of iron deficiency anemia in children with celiac disease [45]. However, a previous study did not find significant differences in the 
prevalence of the DMT1 IVS4+44C $>$ A polymorphism in the hereditary hemochromatosis cohort when compared with the control group [46]. It would be important to investigate the effect of more than one polymorphism of the DMT1 gene on exercise capacity simultaneously, especially checking the possible haplotype on exercise capacity in future studies. (2) We have not checked the serum iron level or tissue iron level. There is currently no report about the effects of DMT1 STR polymorphisms on serum iron levels, while the effects of the DMT1 gene on serum iron level are not conclusive. Mice lacking intestinal DMT1 gene have shown to have extremely low blood iron level [47]. However, patients with DMT1 mutations (GTG deletion in exon 5 and $\mathrm{G} \rightarrow \mathrm{T}$ substitution in exon 8) have normal serum iron level but with a severe liver iron overload [48]. Another mutation of the DMT1 gene (SCL11A2) has been associated with a slight increase of serum iron level, again with severe liver iron overload [49]. Together, these studies suggested that a change in DMT1 gene expression could lead to dysregulation of iron level in blood and tissue, but the exact effects depend on the nature of the polymorphism or mutation. Further studies are warranted to investigate the effects of different DMT1 polymorphisms on serum and tissue iron levels.

\section{Conclusion}

The frequencies of the 258/258 bp homozygous genotype and $258 \mathrm{bp}$ alleles are significantly higher in the elite longdistance runners than in the control group; the DMT1 gene STR polymorphism $258 / 258$ bp genotype may be used as a molecular marker for the talent identification of the elite long-distance runners in Asian population.

\section{Data Availability}

The data used to support the findings of this study are available from the corresponding author upon request.

\section{Conflicts of Interest}

The authors declare that there is no conflict of interest regarding the publication of this paper.

\section{Acknowledgments}

Gerile Wuyun was supported by the China Inner Mongolia Autonomous Region Natural Science Fund (Project Number: 2016MS0317). Yang Hu was supported by the National Key Research and Development Program - Active Health and Ageing Technology Specialty Project (Project Number: 2018YFC2000600). Zihong He was supported by the Chinese Ministry of Science and Technology Winter Olympics Research and Development Project (Project Number: 2018YFF0300402). Yang Hu, Yangchun Li, and Xu Yan were supported by the Beijing Sport University International Cooperation Grant (Project Number: 2018GJ005).

\section{References}

[1] H. Gunshin, B. Mackenzie, U. V. Berger et al., "Cloning and characterization of a mammalian proton-coupled metal-ion transporter," Nature, vol. 388, no. 6641, pp. 482-488, 1997.

[2] J. Kim, R. M. Molina, T. C. Donaghey, P. D. Buckett, J. D. Brain, and M. Wessling-Resnick, "Influence of DMT1 and iron status on inflammatory responses in the lung," American Journal of Physiology. Lung Cellular and Molecular Physiology, vol. 300, no. 4, pp. L659-L665, 2011.

[3] M. D. Fleming, C. C. Trenor, M. A. Su et al., "Microcytic anaemia mice have a mutation in_Nramp2 , a candidate iron transporter gene," Nature Genetics, vol. 16, no. 4, pp. 383-386, 1997.

[4] M. W. Hentze, M. U. Muckenthaler, and N. C. Andrews, "Balancing acts: molecular control of mammalian iron metabolism," Cell, vol. 117, no. 3, pp. 285-297, 2004.

[5] K. Spodaryk, "Iron metabolism in boys involved in intensive physical training," Physiology \& Behavior, vol. 75, no. 1-2, pp. 201-206, 2002.

[6] M. Y. Fang, R. Wu, and J. Cheng, "Iron metabolism and neurodegenerative disease," Chinese Journal of Clinicians(Electronic Edition), vol. 7, p. 4, 2015.

[7] X. Yan, I. Papadimitriou, R. Lidor, and N. Eynon, "Nature versus nurture in determining athletic ability," Medicine and Sport Science, vol. 61, pp. 15-28, 2016.

[8] C. J. Williams, B. J. Gurd, J. T. Bonafiglia et al., “A multi-center comparison of O2peak trainability between interval training and moderate intensity continuous training," Frontiers in Physiology, vol. 10, p. 19, 2019.

[9] L. K. Banting, V. P. Pushkarev, P. Cieszczyk et al., "Elite athletes' genetic predisposition for altered risk of complex metabolic traits,” BMC Genomics, vol. 16, no. 1, p. 25, 2015.

[10] Y. P. Pitsiladis, M. Tanaka, N. Eynon et al., "Athlome Project Consortium: a concerted effort to discover genomic and other "omic" markers of athletic performance," Physiological Genomics, vol. 48, no. 3, pp. 183-190, 2016.

[11] S. Voisin, J. P. Guilherme, X. Yan et al., "ACVR1B rs2854464 is associated with sprint/power athletic status in a large cohort of Europeans but not Brazilians," PLoS One, vol. 11, no. 6, p. e0156316, 2016.

[12] R. Yang, X. Shen, Y. Wang et al., “ACTN3 R577X gene variant is associated with muscle-related phenotypes in elite Chinese sprint/power athletes," Journal of Strength and Conditioning Research, vol. 31, no. 4, pp. 1107-1115, 2017.

[13] X. Yan, N. Eynon, I. D. Papadimitriou et al., "The gene SMART study: method, study design, and preliminary findings," BMC Genomics, vol. 18, Suppl 8, p. 821, 2017.

[14] X. Yan, N. Dvir, M. Jacques et al., "ACE I/D gene variant predicts ACE enzyme content in blood but not the ACE, UCP2, and UCP3 protein content in human skeletal muscle in the Gene SMART study," Journal of Applied Physiology, vol. 125, no. 3, pp. 923-930, 2018.

[15] Y. Hu, "Genetic polymorphism strategy in sports research," Chinese Journal of Sports Medicine, vol. 24, p. 4, 2005.

[16] Z. H. He, "Research strategies and methods for genetic markers of exercise capacity," Chinese Journal of Sports Medicine, vol. 26, p. 8, 2006.

[17] F. Canonne-Hergaux, M. D. Fleming, J. E. Levy et al., "The Nramp2/DMT1 iron transporter is induced in the duodenum of microcytic anemia mk mice but is not properly targeted to 
the intestinal brush border," Blood, vol. 96, no. 12, pp. 39643970, 2000.

[18] P. L. Lee, T. Gelbart, C. West, C. Halloran, and E. Beutler, "The human Nramp2 gene: characterization of the gene structure, alternative splicing, promoter region and polymorphisms," Blood Cells, Molecules, and Diseases, vol. 24, no. 2, pp. 199215, 1998.

[19] Y. Takiyama, K. Sakoe, M. Soutome et al., "Single sperm analysis of the CAG repeats in the gene for Machado-Joseph disease (MJD1): evidence for non-Mendelian transmission of the MJD1 gene and for the effect of the intragenic CGG/GGG polymorphism on the intergenerational instability," Human Molecular Genetics, vol. 6, no. 7, pp. 1063-1068, 1997.

[20] R. L. Stallings, "Distribution of trinucleotide microsatellites in different categories of mammalian genomic sequence: implications for human genetic diseases," Genomics, vol. 21, no. 1, pp. 116-121, 1994.

[21] D. J. Harriss, A. Macsween, and G. Atkinson, "Standards for ethics in sport and exercise science research: 2018 update," International Journal of Sports Medicine, vol. 38, no. 14, pp. 1126-1131, 2017.

[22] M. A. Su, C. C. Trenor, J. C. Fleming, M. D. Fleming, and N. C. Andrews, "The G185R mutation disrupts function of the iron transporter Nramp2," Blood, vol. 92, no. 6, pp. 2157-2163, 1998.

[23] D. Nachtigall, P. Nielsen, R. Fischer, R. Engelhardt, and E. Gabbe, "Iron deficiency in distance Runners A reinvestigation using $59 \mathrm{Fe}$-Labelling and non-invasive liver iron quantification," International Journal of Sports Medicine, vol. 17, no. 07, pp. 473-479, 1996.

[24] O. Kehl, K. Jäger, R. Münch et al., "Mesenterial anemia as a cause of jogging anemia?," Schweizerische medizinische Wochenschrift, vol. 116, no. 29, pp. 974-976, 1986.

[25] O. Han, J. C. Fleet, and R. J. Wood, "Reciprocal regulation of HFE and NNamp2 gene expression by iron in human intestinal cells," The Journal of Nutrition, vol. 129, no. 1, pp. 98-104, 1999.

[26] Y. Liu, "Effects of different intensity exercise on the expression of DMT1 and FP1 protein of duodenum and hepatic hepcidin mRNA in rats," SPORTS SCIENCE, vol. 26, no. 9, p. 68, 2006.

[27] D. Pospisilova, M. P. Mims, E. Nemeth, T. Ganz, and J. T. Prchal, "DMT1 mutation: response of anemia to darbepoetin administration and implications for iron homeostasis," Blood, vol. 108, no. 1, pp. 404-405, 2006.

[28] M. D. Fleming, M. A. Romano, M. A. Su, L. M. Garrick, M. D. Garrick, and N. C. Andrews, "Nramp2 is mutated in the anemic Belgrade (b) rat: evidence of a role for Nramp2 in endosomal iron transport," Proceedings of the National Academy of Sciences of the United States of America, vol. 95, no. 3, pp. 1148-1153, 1998.

[29] J. Beard and B. Tobin, "Iron status and exercise," The American Journal of Clinical Nutrition, vol. 72, no. 2, pp. 594S-597S, 2000.

[30] D. E. Brigham, J. L. Beard, R. S. Krimmel, and W. L. Kenney, "Changes in iron status during competitive season in female collegiate swimmers," Nutrition, vol. 9, no. 5, pp. 418-422, 1993.

[31] M. Arabfard, K. Kavousi, A. Delbari, and M. Ohadi, "Link between short tandem repeats and translation initiation site selection," Human Genomics, vol. 12, no. 1, p. 47, 2018.

[32] D. Tchernitchko, M. Bourgeois, M. E. Martin, and C. Beaumont, "Expression of the two mRNA isoforms of the iron transporter Nramp2/DMTI in mice and function of the iron responsive element," The Biochemical Journal, vol. 363, no. 3, pp. 449-455, 2002.
[33] N. Hubert and M. W. Hentze, "Previously uncharacterized isoforms of divalent metal transporter (DMT)-1: implications for regulation and cellular function," Proceedings of the National Academy of Sciences of the United States of America, vol. 99, no. 19, pp. 12345-12350, 2002.

[34] T. Ganz, "Hepcidin and iron regulation, 10 years later," Blood, vol. 117, no. 17, pp. 4425-4433, 2011.

[35] L. Roecker, R. Meier-Buttermilch, L. Brechtel, E. Nemeth, and T. Ganz, "Iron-regulatory protein hepcidin is increased in female athletes after a marathon," European Journal of Applied Physiology, vol. 95, no. 5-6, pp. 569-571, 2005.

[36] P. Peeling, B. Dawson, C. Goodman et al., "Effects of exercise on hepcidin response and iron metabolism during recovery," International Journal of Sport Nutrition and Exercise Metabolism, vol. 19, no. 6, pp. 583-597, 2009.

[37] I. Auersperger, B. Knap, A. Jerin et al., "The effects of 8 weeks of endurance running on hepcidin concentrations, inflammatory parameters, and iron status in female runners," International Journal of Sport Nutrition and Exercise Metabolism, vol. 22, no. 1, pp. 55-63, 2012.

[38] A. Ishibashi, N. Maeda, D. Sumi, and K. Goto, "Elevated serum hepcidin levels during an intensified training period in welltrained female long-distance runners," Nutrients, vol. 9, no. 3, p. 277, 2017.

[39] N. P. Mena, A. Esparza, V. Tapia, P. Valdés, and M. T. Núñez, "Hepcidin inhibits apical iron uptake in intestinal cells," American Journal of Physiology. Gastrointestinal and Liver Physiology, vol. 294, no. 1, pp. G192-G198, 2008.

[40] B. Chung, T. Chaston, J. Marks, S. K. Srai, and P. A. Sharp, "Hepcidin decreases iron transporter expression in vivo in mouse duodenum and spleen and in vitro in THP-1 macrophages and intestinal Caco-2 cells," The Journal of Nutrition, vol. 139, no. 8, pp. 1457-1462, 2009.

[41] Q. He, T. du, X. Yu et al., "DMT1 polymorphism and risk of Parkinson's disease," Neuroscience Letters, vol. 501, no. 3, pp. 128-131, 2011.

[42] S. M. Saadat, İ. Değirmenci, S. Özkan et al., "Is the 1254T > C polymorphism in the DMT1 gene associated with Parkinson's disease?," Neuroscience Letters, vol. 594, pp. 51-54, 2015.

[43] A. Przybylkowski, G. Gromadzka, and A. Czlonkowska, "Polymorphisms of metal transporter _genes DMT1_ and _ATP7A_ in Wilson's disease," Journal of Trace Elements in Medicine and Biology, vol. 28, no. 1, pp. 8-12, 2014.

[44] D. Wysokinski, M. Zaras, M. Dorecka et al., "An association between environmental factors and the IVS4+44C>A polymorphism of the DMT1 gene in age-related macular degeneration," Graefe's Archive for Clinical and Experimental Ophthalmology, vol. 250, no. 7, pp. 1057-1065, 2012.

[45] C. Tolone, G. Bellini, F. Punzo et al., "The DMT1 IVS4 $+44 \mathrm{C}>\mathrm{A}$ polymorphism and the risk of iron deficiency anemia in children with celiac disease," PLoS One, vol. 12, no. 10, p. e0185822, 2017.

[46] T. Kelleher, E. Ryan, S. Barrett, C. O'Keane, and J. Crowe, "DMT1 genetic variability is not responsible for phenotype variability in hereditary hemochromatosis," Blood Cells, Molecules \& Diseases, vol. 33, no. 1, pp. 35-39, 2004.

[47] A. Shawki, S. R. Anthony, Y. Nose et al., "Intestinal DMT1 is critical for iron absorption in the mouse but is not required for the absorption of copper or manganese," American Journal of Physiology. Gastrointestinal and Liver Physiology, vol. 309, no. 8, pp. G635-G647, 2015. 
[48] C. Beaumont, J. Delaunay, G. Hetet, B. Grandchamp, M. de Montalembert, and G. Tchernia, "Two new human DMT1 gene mutations in a patient with microcytic anemia, low ferritinemia, and liver iron overload," Blood, vol. 107, no. 10, pp. 4168-4170, 2006.

[49] A. Iolascon, M. d'Apolito, V. Servedio, F. Cimmino, A. Piga, and C. Camaschella, "Microcytic anemia and hepatic iron overload in a child with compound heterozygous mutations in DMT1 (SCL11A2)," Blood, vol. 107, no. 1, pp. 349-354, 2006. 


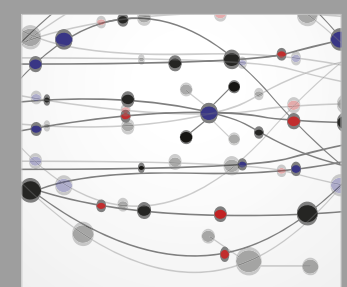

The Scientific World Journal
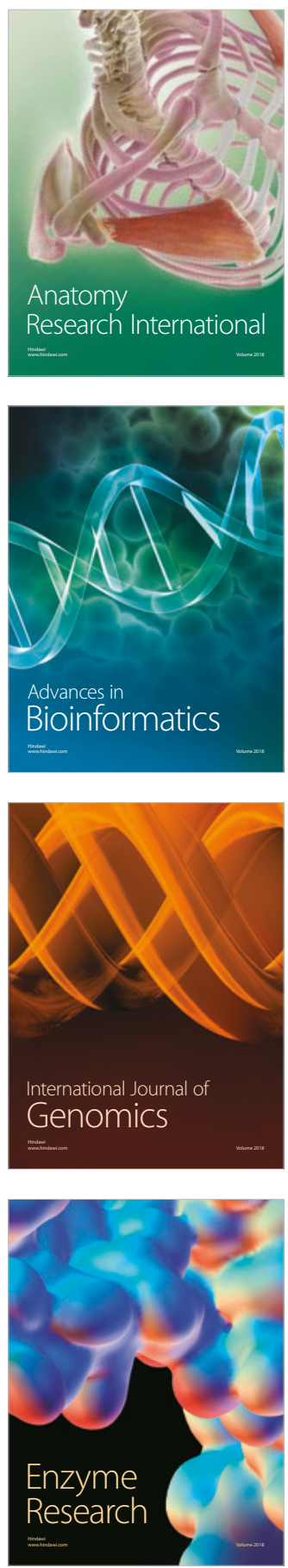
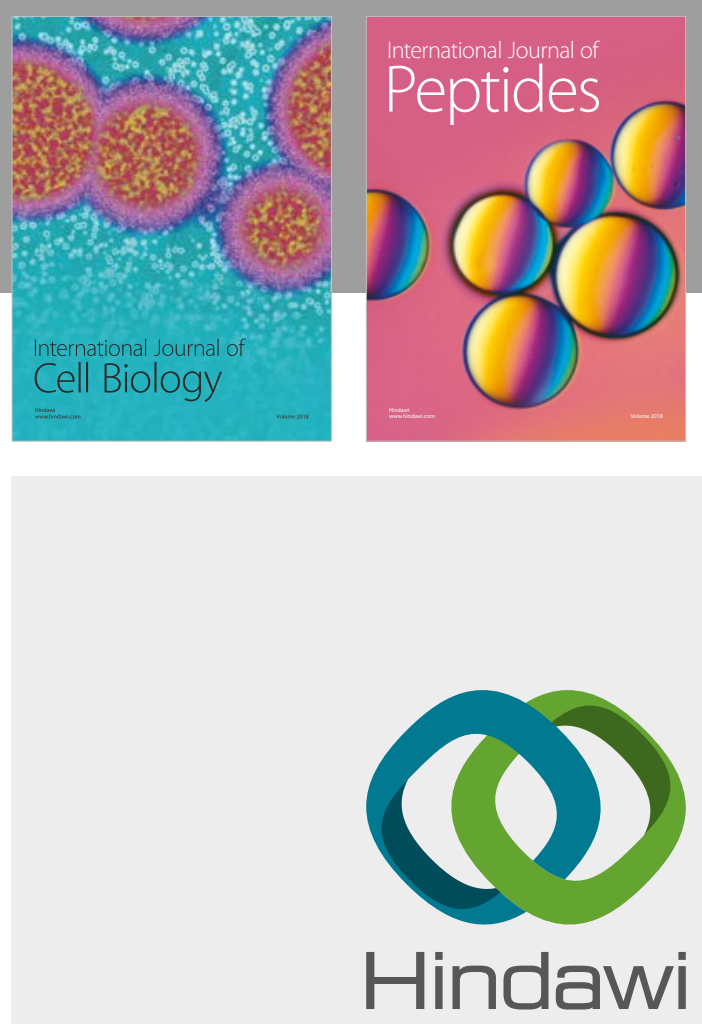

Submit your manuscripts at

www.hindawi.com
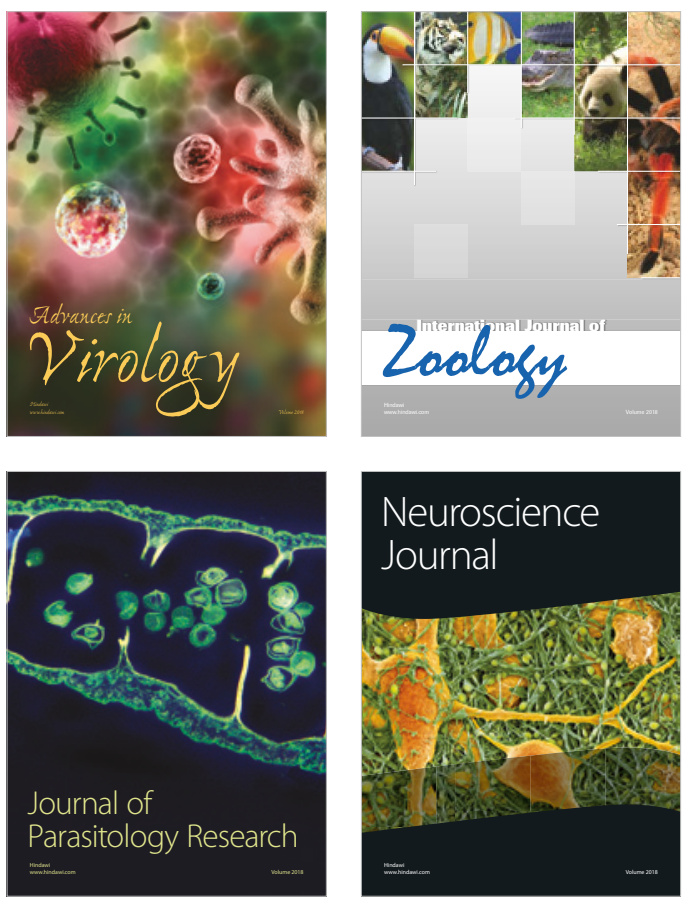
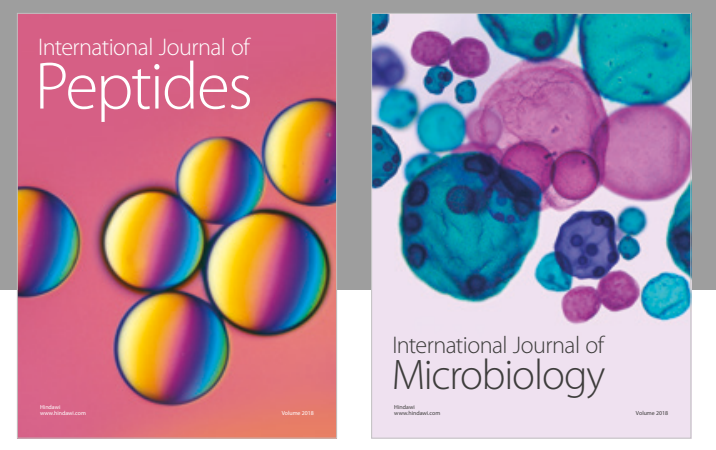

nternational Journal of Microbiology
Journal of
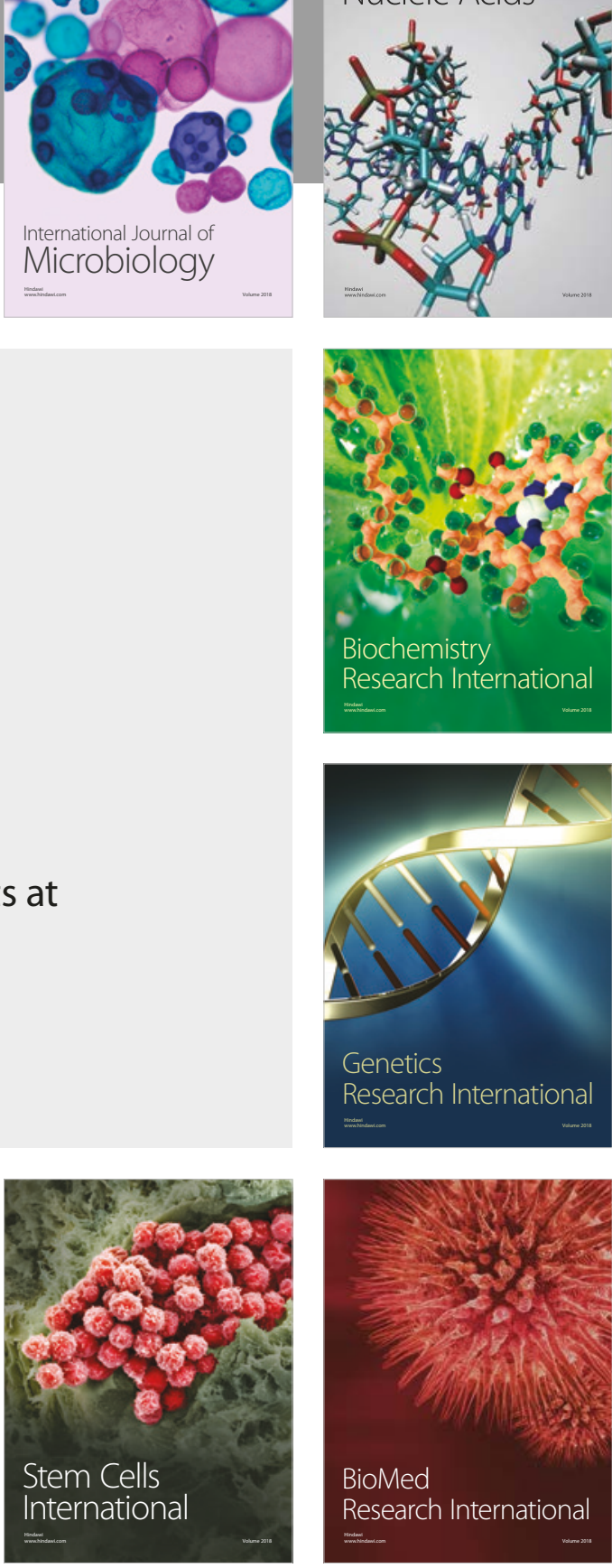
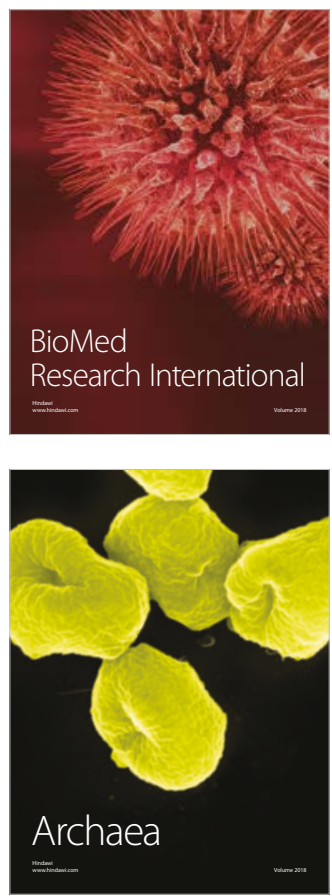